\title{
Structural Protection of Ancient Masonry Pagodas Based on Modified Epoxy Resin Infiltration
}

\author{
Yuan Zhou ${ }^{1,3^{*}}$, Fei Zhang ${ }^{2,3}$ and Sheliang Wang ${ }^{3}$ \\ ${ }^{1}$ College of Science, Chang'an University, Xi' an 710061, China \\ ${ }^{2}$ Shaanxi Construction Engineering Group Corporation Limited, Xi'an 710003, China \\ ${ }^{3}$ School of Civil Engineering, Xi'an University of Architecture and Technology, Xi'an 710055, China
}

\section{Corresponding Author Email: cz1979@ chd.edu.cn}

\begin{abstract}
Following the two principles of ancient pagoda protection (i.e. safety first and minimum intervention), this paper attempts to reinforce ancient masonry structures with organic polymer materials, and puts forward the modified epoxy resin (MER) infiltration, a nondestructive reinforcement method for ancient pagodas. A total of 12 specimens in 4 groups were prepared from sticky rice mortar (SRM), and used to test whether the MER infiltration could enhance the masonry structure of ancient pagodas, and explore the constitutive relation of MER-reinforced pagoda structure. The test results show that the MER-reinforced specimens were $40.5 \%, 11 \%$ and $26.7 \%$ greater than the original specimens in compressive strength, shear strength and elastic modulus, respectively. Therefore, the MER can effectively reinforce ancient masonry structures. To further verify the effectiveness of our method, the Small Wild Goose (SWG) Pagoda in Xi' an, China, was reinforced by the MER and subjected to vulnerability analysis. The analysis reveals that the MER-reinforced structure is less likely to fail under each level than the original structure. Therefore, the MER provides an effective tool and a good reference for nondestructive protection of ancient brick masonry pagodas.
\end{abstract}

Keywords: ancient pagoda, masonry structure, modified epoxy resin (MER), vulnerability; constitutive relation Received: December-06-2019, Accepted: January-15-2020, https://doi.org/10.14447/jnmes.v23i1.a03

\section{INTRODUCTION}

Ancient pagodas boast rich cultural and artistic values, thanks to their elegant shapes, diverse structures and varied building materials. However, most ancient pagodas have undergone natural disasters and manmade damages. The surviving ones are generally damaged in varied degrees, and even on the verge of collapse and total destruction. Therefore, the protection of ancient pagodas has become a hotspot in structural engineering.

Many domestic and foreign scholars have probed deep into the protection of ancient pagodas. For example, Capozucca et al. reinforced two seismically-damaged old brick walls with carbon fiber strips, and conducted low-cycle repeated loading tests on the reinforced walls, revealing that the reinforcement had improved the walls in shear strength, ductility and energydissipating capacity and reduced the surface cracks on the specimens. Ricci et al. carried out a pseudo-static test on ancient masonry walls reinforced by glass fiber composites; the test results show an obvious increase of the masonry structure in shear capacity, which agrees well with their theoretical model [1, 2]. Witzany et al. [3] enhanced the bearing capacity of an ancient masonry structure, which had been reinforced by fiber-reinforced polymer (FRP) composite: the two ends of the structure were anchored by steel bars, and then fiber cloth was pasted at the ends to constrain the walls. Ashraf et al. [4] resorted to cement grouting and steel mesh pasting to reinforce brick walls with openings for doors and windows that had been damaged by seismic tests.

In addition, some scholars explored the compressive capacity and horizontal bearing capacity of an old brick wall reinforced by steel mesh and cement mortar and set up a simplified brick masonry wall tube for a seismically-damaged ancient brick pagoda, and reinforced the wall tube through grouting and hooping. Related research tested the seismic resistance of cracked walls reinforced with carbon fiber cloths. Compressive and shear tests were conducted on masonry specimens constructed with materials used in ancient buildings and reinforced by grouting, and concluded that the grouting had improved the mortar performance, integrity and strength of the masonry specimens [5-11].

To sum up, there is abundant practical research on the protection of ancient masonry pagodas, which greatly enriches the engineering experience. In most cases, however, the masonry structure is reinforced by materials like carbon cloth fiber. These materials must be pasted on one or both sides of the structure, disturbing the original appearance of the ancient pagodas. This calls for a novel strategy that protects the masonry structure and preserves the original appearance of the ancient building.

Following the two principles of ancient pagoda protection (i.e. safety first and minimum intervention), this paper puts forward a nondestructive reinforcement method for ancient pagodas: modified epoxy resin (MER) infiltration, and verifies the effectiveness of our method through tests and analysis.

\section{MASONRY MORTAR TESTS}

Located in Xi'an, China, the Small Wild Goose (SWG) Pagoda is a typical ancient masonry pagoda. Taking the SWG Pagoda as an example, this paper uses sticky rice mortar (SRM) 
to represent the structural materials of the SWG Pagoda, and reinforced the SRM separately with modified epoxy resin (MER), methyl methacrylate (MMA) and sodium methyl silicate (SMS).

Due to the particularity of ancient masonry structure, there is no standard for mechanical evaluation of ancient masonry mortar. In this research, the mechanical properties of the original and modified SRMs were observed through a compression test on cubic specimens and an uniaxial compression test on prism specimens, according to the Standard for Test Method of Basic Properties of Construction Mortar (JGJ/T70-2009). The test results were analyzed to disclose how the additional materials affect the strength, stress and strain of the SRM.

\subsection{Specimen preparation}

The original and modified SRMs were made into cubic specimens and prism specimens. Each cubic specimen is $70.7 \mathrm{~mm} \times 70.7 \mathrm{~mm} \times 70.7 \mathrm{~mm}$ in size, and each prism specimen is $70.7 \mathrm{~mm} \times 70.7 \mathrm{~mm} \times 216 \mathrm{~mm}$ in size. The specimens were let stand for $2 \mathrm{~d}$ before being numbered and demolded. The demolded specimens were naturally cured to the required age of $28 \mathrm{~d}$. The serial numbers of cubic and prism specimens are listed in Tables 1 and 2, respectively.

Table 1. Cubic specimens

\begin{tabular}{ccccc}
\hline \multirow{2}{*}{ Substrate } & \multicolumn{4}{c}{ Additional material } \\
& None & MER & MMA & SMS \\
\hline SRM & SC1 SC3 & SEC1 SEC3 & SMC1 SMC3 & SSC1 SSC3 \\
\hline
\end{tabular}

Table 2. Prism specimens

\begin{tabular}{ccccc}
\hline \multirow{2}{*}{ Substrate } & \multicolumn{4}{c}{ Additional material } \\
& None & MER & MMA & SMS \\
\hline SRM & SP1 SP3 & SEP1 SEP3 & SMP1 SMP3 & SSP1 SSP3 \\
\hline
\end{tabular}

Table 3. Test results on cubic SRM specimens

\begin{tabular}{cccccc}
\hline Name & $\begin{array}{c}\text { Specimen } \\
\text { number }\end{array}$ & $\begin{array}{c}\text { Failure } \\
\text { load/kN }\end{array}$ & $\begin{array}{c}\text { Bearing } \\
\text { area/mm }\end{array}$ & $\begin{array}{c}\text { Compressive } \\
\text { strength/MPa }\end{array}$ & $\begin{array}{c}\text { Mean compressive } \\
\text { strength /MPa }\end{array}$ \\
\hline \multirow{3}{*}{$\mathrm{SRM}$} & $\mathrm{SC}_{1}$ & 6.75 & $4,998.49$ & 1.4 & \\
& $\mathrm{SC}_{2}$ & 6.44 & $4,998.49$ & 1.3 & 1.8 \\
& $\mathrm{SC}_{3}$ & 7.29 & $4,998.49$ & 1.5 & \\
\hline
\end{tabular}

Table 4. Test results on cubic reinforced specimens

\begin{tabular}{|c|c|c|c|c|c|c|}
\hline $\begin{array}{c}\text { Additional } \\
\text { material }\end{array}$ & $\begin{array}{c}\begin{array}{c}\text { Specimen } \\
\text { number }\end{array} \\
\end{array}$ & $\begin{array}{l}\text { Failure } \\
\text { load/kN }\end{array}$ & $\begin{array}{c}\text { Bearing } \\
\text { area } / \mathbf{m m} 2\end{array}$ & $\begin{array}{c}\text { Compressive } \\
\text { strength/MPa }\end{array}$ & $\begin{array}{c}\text { Mean compressive } \\
\text { strength } / \mathrm{MPa}\end{array}$ & $\begin{array}{c}\text { Increment of compressive } \\
\text { strength } / \%\end{array}$ \\
\hline \multirow{3}{*}{ MER } & SEC1 & 10.53 & $4,998.49$ & 2.1 & \multirow[t]{3}{*}{ 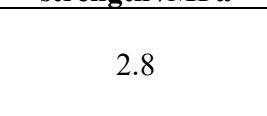 } & \multirow{3}{*}{$55.6 \%$} \\
\hline & SEC2 & 9.60 & $4,998.49$ & 1.9 & & \\
\hline & SEC3 & 11.74 & $4,998.49$ & 2.3 & & \\
\hline \multirow{3}{*}{ MMA } & SMC1 & 10.33 & $4,998.49$ & 2.1 & \multirow{3}{*}{2.5} & \multirow{3}{*}{$38.9 \%$} \\
\hline & SMC2 & 9.21 & $4,998.49$ & 1.8 & & \\
\hline & SMC3 & 9.40 & $4,998.49$ & 1.9 & & \\
\hline \multirow{3}{*}{ SMS } & $\mathrm{SSC} 1$ & 8.64 & $4,998.49$ & 1.7 & \multirow{3}{*}{2.1} & \multirow{3}{*}{$17.8 \%$} \\
\hline & $\mathrm{SSC}_{2}$ & 7.15 & $4,998.49$ & 1.4 & & \\
\hline & $\mathrm{SSC}_{3}$ & 8.68 & $4,998.49$ & 1.7 & & \\
\hline
\end{tabular}

\subsection{Compression test on cubic specimens}

The compression test on cubic specimens was conducted as shown in Figure 1. The test results on cubic SRM specimens and cubic reinforced specimens are recorded in Tables 3 and 4 , respectively.

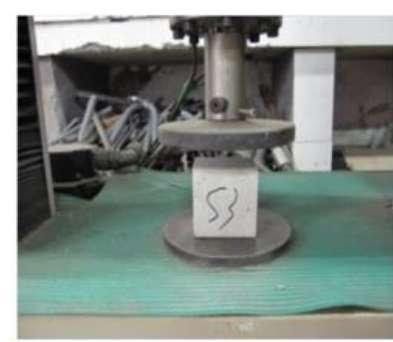

(a) Test setup

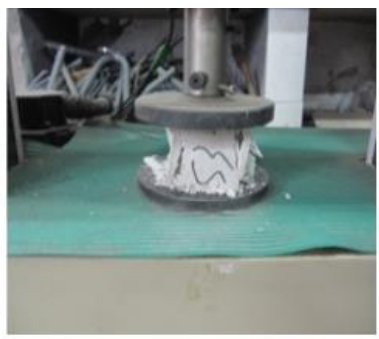

(b) Failure mode
Figure 1. The compression test on cubic specimens
It can be seen that all of the three nondestructive reinforcement materials increased the compressive strength of cubic SRM specimens in varied degrees. The increment of compressive strength was $55.6 \%, 38.9 \%$ and $17.8 \%$ after the addition of MER, MMA and SMS, respectively. Obviously, the MER achieved the best enhancement effect on the compressive strength of the SRM.

\subsection{Uniaxial compression test on prism specimens}

For the lack of space, the setup and failure mode of the uniaxial compression test are not reported here. The main results of the test are listed in Table 5 below. After adding MER, MMA and SMS, the peak stress of prism SRM specimens increased by $40.7 \%, 22.8 \%$ and $18.2 \%$, the peak strain increased by $37.6 \%, 31.3 \%$ and $26.8 \%$, the ultimate strain increased by $36.9 \%, 31.0 \%$ and $31.7 \%$, and the elastic modulus increased by $35.1 \%, 32.3 \%$ and $29.3 \%$, respectively. 


\section{/ J. New Mat. Electrochem. Systems}

The results show that all the three reinforcement materials can improve the peak stress of prism SRM specimens. The best enhancing effect belongs to the MER.

Table 5. Test results on prism specimens

\begin{tabular}{ccccc}
\hline $\begin{array}{c}\text { Specimen } \\
\text { group }\end{array}$ & $\begin{array}{c}\text { Peak } \\
\text { stress/MPa }\end{array}$ & $\begin{array}{c}\text { Peak } \\
\text { strain }\end{array}$ & $\begin{array}{c}\text { Ultimate } \\
\text { strain }\end{array}$ & $\begin{array}{c}\text { Elastic modulus } \\
\text { E/MPa }\end{array}$ \\
\hline SP & 0.4434 & 0.0112 & 0.0142 & 26.1 \\
SEP & 0.5909 & 0.0159 & 0.0196 & 83.3 \\
SMP & 0.5747 & 0.0158 & 0.0193 & 82.2 \\
SSP & 0.5425 & 0.0142 & 0.0187 & 76.3 \\
\hline
\end{tabular}

In summary, the MER can effectively enhance the strength of ancient masonry mortar. Thus, it is reasonable to adopt the MER for the nondestructive enhancement and performance test of ancient masonry pagodas like the SWG Pagoda.

\section{NONDESTRUCTIVE TESTING OF REINFORCED MASONRY STRUCTURES}

Based on the structural materials of the SWG Pagoda, black bricks and SRM were selected to prepare specimens for tests on compressive strength and shear strength. The specimens were reinforced by the MER infiltration. The infiltration procedure is illustrated in Figure 2 below.

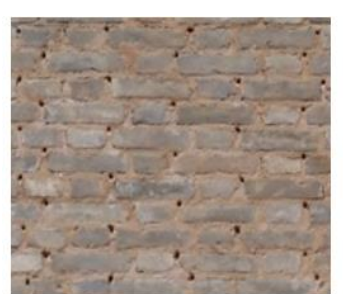

(a) Drilling infiltration holes

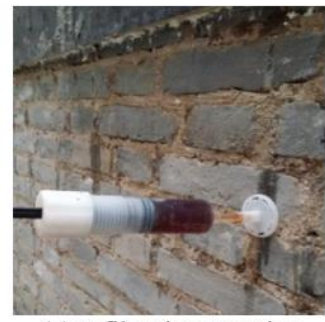

(c) Infiltration grouting

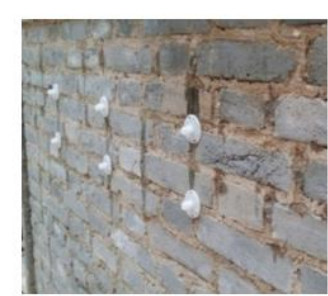

(b) Installing grouting device

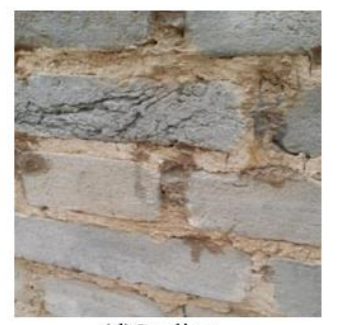

(d)Sealing
Figure 2. The procedure of MER infiltration

\subsection{Compressive strength test}

According to the Standard for Test Method of Basic Mechanics Properties of Masonry (GB/T50129-2011), black bricks and SRM were adopted to prepare six specimens $240 \mathrm{~mm}$ in thickness, $750 \mathrm{~mm}$ in height and $370 \mathrm{~mm}$ in width [12].

The height to thickness ratio (3.12) fell in the range required by GB/T50129-2011. The six specimens were divided evenly into two groups. The specimens in one group were taken as control specimens, while those in the other group were reinforced by MER. After that, each specimen was covered by four layers of bricks for $14 \mathrm{~d}$, and then cured for $28 \mathrm{~d}$ in the test room at $20^{\circ} \mathrm{C}$.

During the compressive strength test (Figure 3), 5\% of predicted damage load was applied to the specimen to check the sensitivity and stability of the instruments. Next, the load was increased at a constant rate in $1.0-1.5 \mathrm{~min}$ to $15 \%$ of the predicted damage load, and then maintained for 1-2min. After that, the load was increased again and maintained in the same manner. The phased load increase continued until the pointer of the pressure testing machine suddenly moved back, i.e. the specimen failed. The load at this time was recorded as the failure load of the specimen.

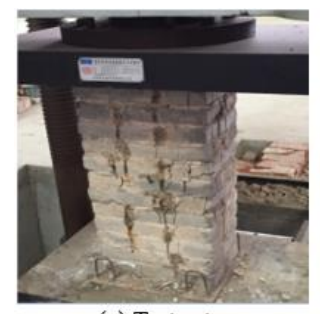

(a) Test setup

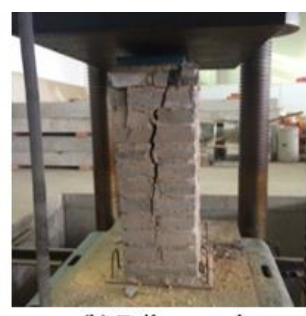

(b) Failure mode
Figure 3. The compressive strength test

After removing the invalid data points, the measured data were used to fit the compressive stress-strain curve of the specimens. As shown in Figure 4, the curve was approximately linear in the initial phase of loading, indicating that the specimens are in the elastic state. With the growing load, the strength and deformation of MER-reinforced specimens both improved to a certain extent. This means the MER can effectively reinforce the masonry structure of the SWG Pagoda.

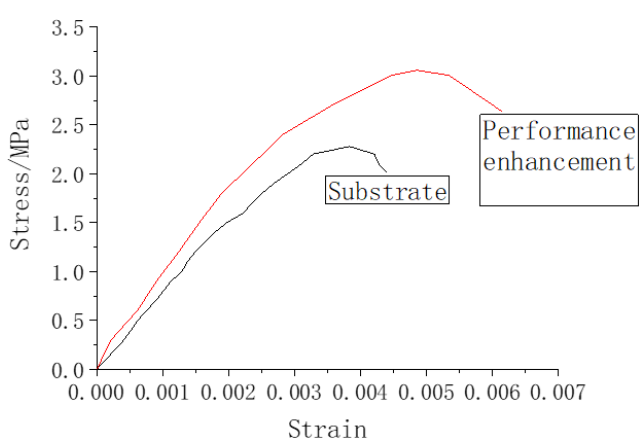

Figure 4. The compressive stress-strain curve of reinforced specimens

\subsection{Shear strength test}

As required by GB/T50129-2011, black bricks and SRM were adopted to prepare six specimens for shear strength test. Each specimen contains nine bricks (Figures 5 and 6). The six specimens were also divided evenly into two groups. The specimens in one group were taken as control specimens, while those in the other group were reinforced by MER.
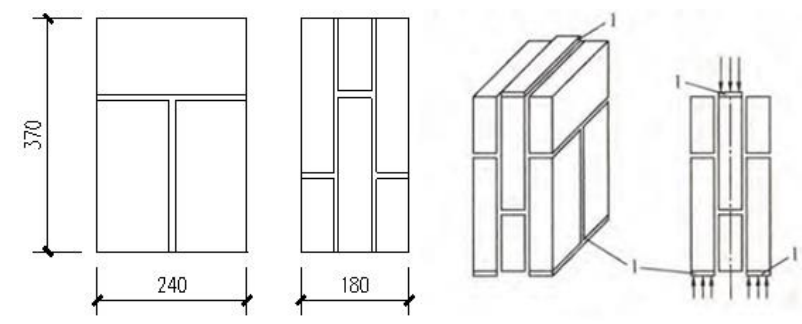

Figure 5. Specimen structure and stress diagram 


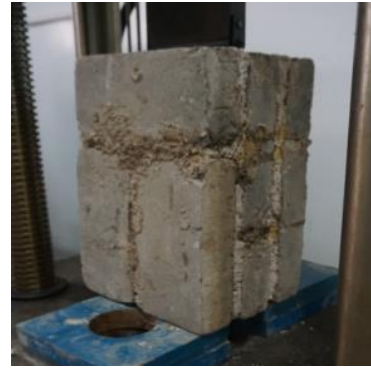

Figure 6. The photo of a specimen

To ensure the consistency between shear strength test and compressive strength test, the specimens for the two tests were prepared at the same time by the same group of workers from the same batch of materials. During the preparation, the vertical mortar joints of each specimen were always fully filled. The prepared specimens were covered by plastic films for wet curing.

Before the shear strength test, the specimen was placed vertically on the lower plate of the test machine in such a manner that the specimen centerline coincides with the axis of the upper and lower plates and that the specimen is in close contact with the lower plate. Once the test started, the load was applied continuously at a constant rate. To prevent impact load, the loading rate was controlled such that the specimen fails, i.e. one of the shearing sections is damaged, in 1-3min. At this time, the load was recorded as the damage load of the specimen.

Figures 7 and 8 display the test setups and failure modes of SRM specimens and reinforced specimens, respectively. In the initial phase of loading, no sign of cracking was observed on the mortar-brick interface of the reinforced specimens. With the growing load, some fine cracks appeared on the interface, mainly in the upper part of the specimens. Further load increase induced the cracks to propagate toward the center of the specimens and widen significantly. Eventually, the specimens failed under the shear load on one side: the interface was cut off and a part of the specimen was separated.

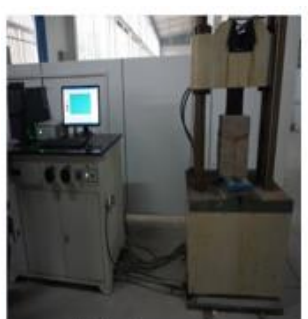

(a) Test setup

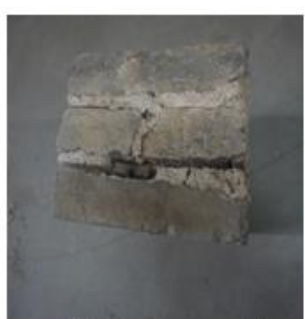

(b) Failure mode
Figure 7. The shear strength test on SRM specimens

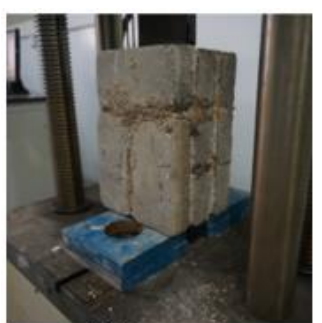

(a) Test setup

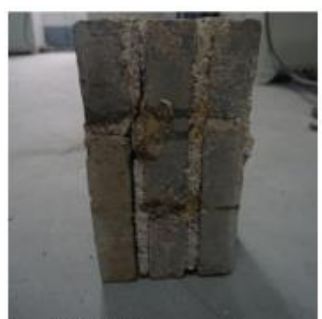

(b) Failure mode
Figure 8. The shear strength test on reinforced specimens

\subsection{Results analysis}

\subsubsection{Results of compressive strength test}

The mechanical properties of the specimens for compressive strength test were calculated by the methods mentioned in GB/T50129-2011. The calculated results are accurate to $0.01 \mathrm{~N} / \mathrm{mm} 2$ and listed in Table 6 . The masonry of the SWG Pagoda is an elastoplastic material, whose stressstrain relationship changes continuously. According to the stress-strain curve, the secant modulus at the stress $\sigma$ of 0.4 was taken as the elastic modulus of each specimen. The elastic moduli of all specimens are given in Table 7.

Table 6. The mechanical properties of the specimens for compressive strength test

\begin{tabular}{cccc}
\hline $\begin{array}{c}\text { Specimen } \\
\text { number }\end{array}$ & $\begin{array}{c}\text { Failure } \\
\text { load /kN }\end{array}$ & $\begin{array}{c}\text { Compressive } \\
\text { strength/MPa }\end{array}$ & $\begin{array}{c}\text { Mean compressive } \\
\text { strength/MPa }\end{array}$ \\
\hline Original 1 & 199.80 & 2.25 & \\
Original 2 & 204.24 & 2.30 & 2.27 \\
Original 3 & 202.46 & 2.28 & \\
Reinforced 1 & 285.05 & 3.21 & \\
Reinforced 2 & 280.61 & 3.16 & 3.19 \\
Reinforced 3 & 282.38 & 3.18 & \\
\hline
\end{tabular}

Table 7. The elastic moduli of the specimens for compressive strength test

\begin{tabular}{ccc}
\hline Group & $\begin{array}{c}\text { Compressive } \\
\text { strength } / \mathbf{M P a}\end{array}$ & $\begin{array}{c}\text { Elastic modulus } \\
\left(\mathbf{N} / \mathbf{m m}^{\mathbf{2}}\right)\end{array}$ \\
\hline Original & 2.27 & 852 \\
Reinforced & 3.19 & 1,080 \\
\hline
\end{tabular}

Table 8. The mechanical properties of the specimens for shear strength test

\begin{tabular}{cccc}
\hline $\begin{array}{c}\text { Specimen } \\
\text { number }\end{array}$ & $\begin{array}{c}\text { Failure } \\
\text { load /kN }\end{array}$ & $\begin{array}{c}\text { Shear } \\
\text { strength/MPa }\end{array}$ & $\begin{array}{c}\text { Mean shear } \\
\text { strength /MPa }\end{array}$ \\
\hline Original 1 & 4.32 & 0.048 & \\
Original 2 & 3.73 & 0.042 & 0.045 \\
Original 3 & 4.05 & 0.046 & \\
Reinforced 1 & 4.65 & 0.052 & \\
Reinforced 2 & 4.37 & 0.049 & 0.050 \\
Reinforced 3 & 4.39 & 0.049 & \\
\hline
\end{tabular}

\subsubsection{Results of shear strength test}

In the light of the GB/T50129-2011, the shear strength $f_{v, i}$ of each specimen along a single section of the joint was computed, and recorded in Table 8. Considering the small shear strength of the masonry, the shear strengths of the specimens were accurate to $0.001 \mathrm{~N} / \mathrm{mm}^{2}$, aiming to ensure the accuracy of the test results.

Tables 6-8 show that the MER-reinforced specimens were $40.5 \%, 11 \%$ and $26.7 \%$ greater than the original specimens in compressive strength, shear strength and elastic modulus, respectively. Therefore, the MER can effectively reinforce the ancient masonry structure.

\subsubsection{Constitutive relation of MER-reinforced masonry}

Based on the stress features of the ancient masonry structure, the test data were sorted out, processed and imported to the parabolic constitutive model proposed by Hendry et al. [13], producing the constitutive relation of MER-reinforced specimens under compression: 


$$
\frac{\sigma}{\sigma_{0}}=1.57\left(\frac{\varepsilon}{\varepsilon_{0}}\right)-0.58\left(\frac{\varepsilon}{\varepsilon_{0}}\right)^{2.79}
$$

The constitutive relation of formula (1) was derived from the results of compressive strength test on the MER-reinforced specimens prepared from materials similar to those of the SWG Pagoda. The specimens must have high similarity in mechanical properties with MER-reinforced masonry structure of the pagoda. Therefore, the constitutive relation of MER-reinforced pagoda was extended from formula (1) by correcting the parameters according to the elastic modulus ratio between the MER-reinforced pagoda and the MERreinforced specimens. Through the correction, the elastic modulus equals the measured value of the MER-reinforced pagoda. Hence, the constitutive relation of MER-reinforced pagoda can be expressed as:

$$
\frac{\sigma}{\sigma_{0}}=1.26\left(\frac{\varepsilon}{\varepsilon_{0}}\right)-0.47\left(\frac{\varepsilon}{\varepsilon_{0}}\right)^{2.79}
$$

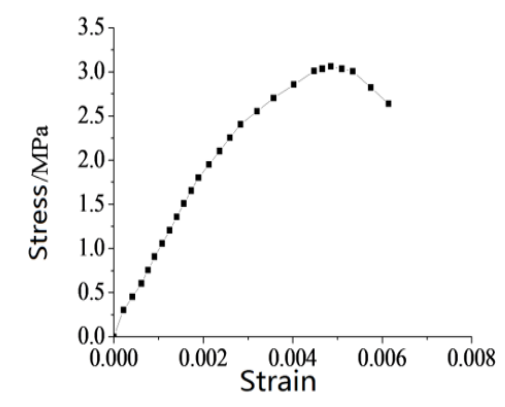

(a) The stress-strain curve of MER-reinforced specimens

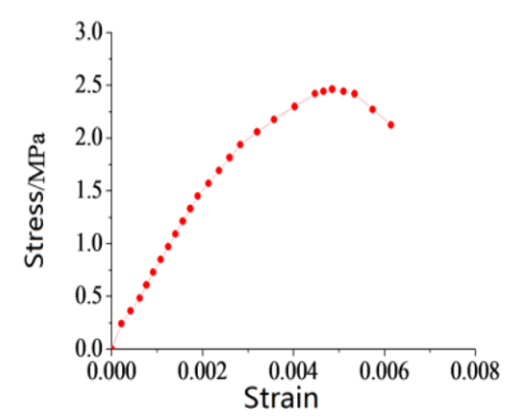

(b) The stress-strain curve of MER-reinforced pagoda

Figure 9. The stress-strain curves after MER reinforcement

Formula (2) was taken as the constitutive relation of MERreinforced pagoda in the subsequent analysis, and used to configure the relevant parameters in each phase under compression. Figure 9 presents the stress-strain curves of the MER-reinforced specimens and pagoda.

\section{SEISMIC VULNERABILITY OF MER- REINFORCED MASONRY STRUCTURE}

The above analysis shows that the MER infiltration can obviously improve the mechanical performance of ancient masonry. If applied to brick masonry ancient pagodas, the MER infiltration will definitely change the mechanical performance of the pagoda structure. This section aims to verify whether the MER reinforcement could improve the seismic performance of the SWG pagoda.

The entire SWG Pagoda was subjected to finite-element modelling. For the masonry material, the elastic modulus, density and Poisson's ratio were set to $890.7 \mathrm{MPa}, 1,200 \mathrm{~kg} / \mathrm{m}^{3}$ and 0.15 , respectively. For the concrete floors, the elastic modulus, density and Poisson's ratio were set to $3.0 \times 10^{4} \mathrm{MPa}$, $2,400 \mathrm{~kg} / \mathrm{m}^{3}$ and 0.16 , respectively. The structural model and finite-element model of the SWG Pagoda are displayed in Figure 10.

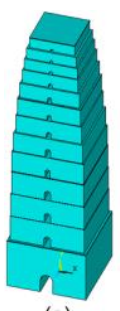

(a)

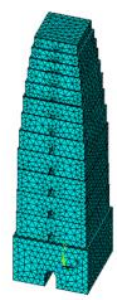

(b)
Figure 10. The models of the SWG Pagoda ((a) Structural model; (b) Finite-element model)

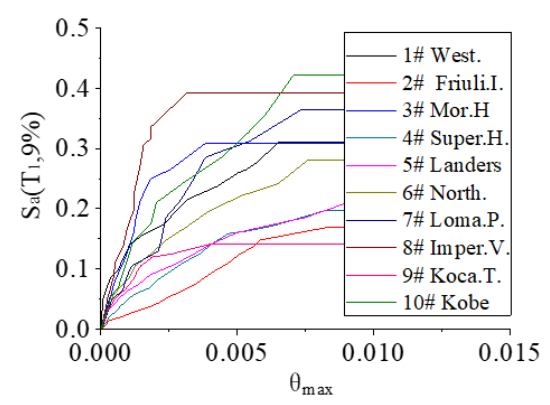

Figure 11. The IDA curves under the ten seismic waves

Ten seismic waves were selected and amplitude-modulated by hunt-and-fill method. Empirically, the intensity measure (IM) for seismic response was defined as the spectral acceleration $\left(S_{a}\right)$ with a period of $T_{1}$ (the structure's fundamental period) and a damping ratio of $9 \%$, denoted here as $S_{a}\left(T_{1}, 9 \%\right)(\mathrm{Fu}, 2001)$; the damage measure $(\mathrm{SM})$ for seismic response was defined as the maximum inter-story drift ratio $\theta_{\max }$. The MER-reinforced pagoda structure was subjected to incremental dynamic analysis (IDA) $[14,15]$.

The resulting IDA curves (Figure 11) were statistically analyzed. The analysis results are displayed in Figure 12. The scatter plot of In $(S a)$-In $\left(\theta_{\max }\right)$ and the results of linear regression analysis are shown in Figure 13.

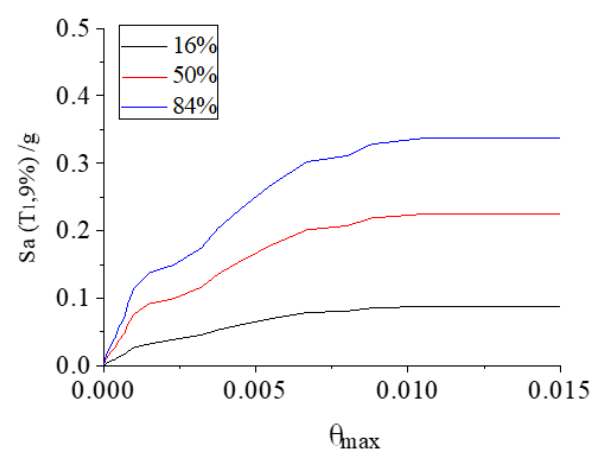

Figure 12. The fractional curves 


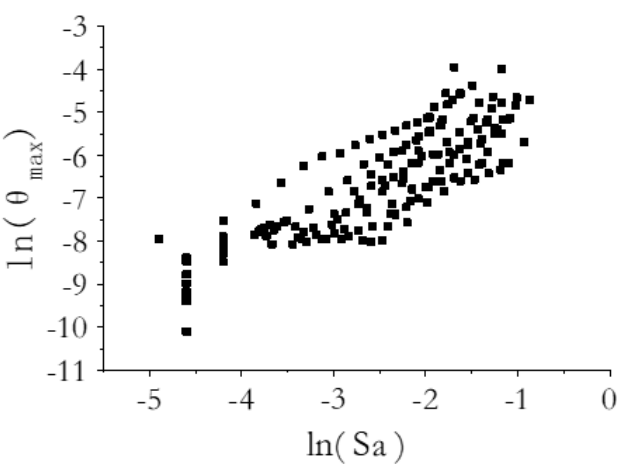

(a) Scatterplot

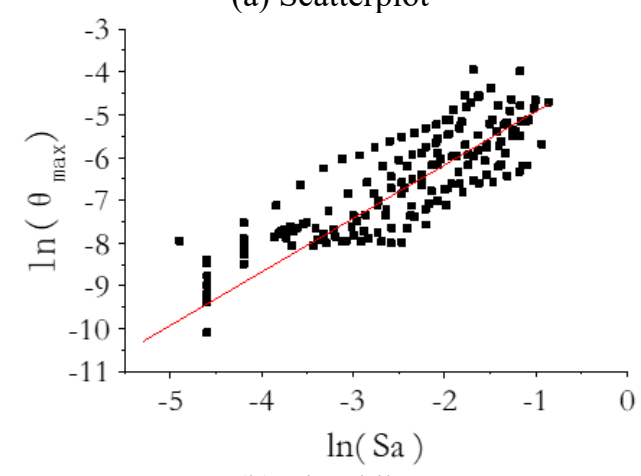

(b) Fitted line

Figure 13. The results of linear regression

As shown in Figure 13, the linear regression equation can be expressed as:

$$
\ln \left(\theta_{\max }\right)=-4.3125+1.0509 \times \ln \left(\mathrm{Sa}\left(T_{1}, 9 \%\right)\right)
$$

From formula (3), it can be deduced that $a=\ln (a)=-4.3125$. Thus, we have $\alpha=0.0134, b=\beta=1.0509$. Then, the structural capacity of each limit state could be ascertained, according to the relevant provisions and definitions. Substituting the capacities to the limit-state failure probability formula, we have:

$$
P_{f}\left(S_{a}\right)=\Phi\left(-\frac{\ln \left[0.0134\left(S_{a}\left(T_{1}, 9 \%\right)\right)^{1.0509} / \bar{c}\right]}{\sqrt{\beta_{c}^{2}+\beta_{d}^{2}}}\right)
$$

where, $P_{f}$ is the probability that the structural response reaches or exceeds a performance level; $\bar{c}$ is the mean structural capacity (usually the median of structural capacity); $\Phi(x)$ is the standard normal distribution; $\beta(c)$ and $\beta(d)$ can be valued by FEMA350 based on the seismic vulnerability curve of the structure: If $S a\left(T_{1}, 9 \%\right)$ serves as the independent variable of the curve, $\sqrt{\beta_{c}^{2}+\beta_{d}^{2}}$ equals 0.4 . The $\Phi(x)$ function can be expressed as:

$$
n(x)=\frac{1}{\sqrt{2 \pi}} \int_{-\infty}^{x} \exp \left(-\frac{t^{2}}{2}\right) d t
$$

The seismic vulnerability of the MER-reinforced pagoda structure was fully analyzed. The seismic vulnerabilities of the structure under different seismic waves are presented in Figure 14 below.

It can be seen from Figure 14 that the seismic vulnerability of the MER-reinforced pagoda structure obeyed similar trends with that of the original structure, but differed greatly in magnitude. Table 9 compares the failure probabilities of the original and enhancement structures at different levels of seismic vulnerability curve under $S a\left(T_{1}, 9 \%\right)=0.05 \mathrm{~g}$.

Table 9 shows that the MER reinforcement reduced the failure probability by $24.27 \%$ under the level of normal use, $4.55 \%$ under the level of temporary use, $0.51 \%$ under the level of life safety, and by $0 \%$ under the level of collapse prevention. The results indicate that the MER-reinforced structure is less likely to fail under each level than the original structure. Therefore, the MER infiltration can effectively enhance the mechanical properties of the ancient masonry structure.

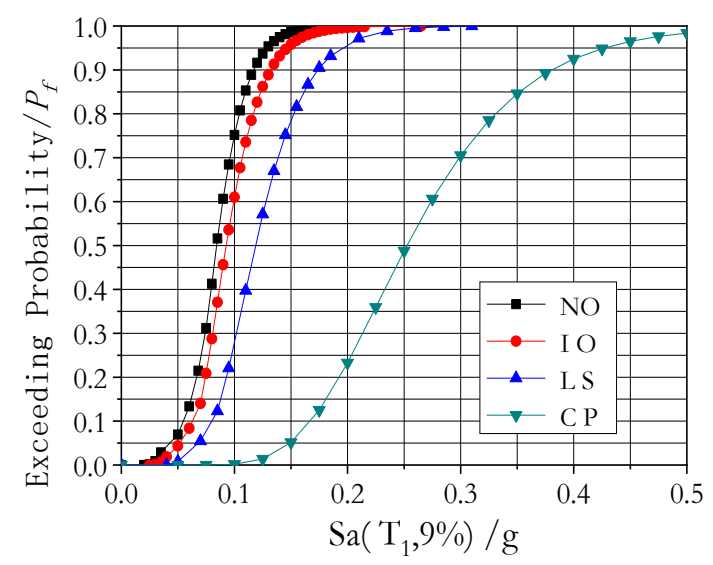

Figure 14. The seismic vulnerability curves of the MERreinforced pagoda structure

Table 9. The seismic vulnerabilities of the reinforced and original structures under $S_{a}\left(T_{1}, 9 \%\right)=0.05 \mathrm{~g}$

\begin{tabular}{ccccc}
\hline $\begin{array}{c}\text { Failure } \\
\text { probability }\end{array}$ & $\begin{array}{c}\text { Normal } \\
\text { use }\end{array}$ & $\begin{array}{c}\text { Temporary } \\
\text { use }\end{array}$ & $\begin{array}{c}\text { Life } \\
\text { safety }\end{array}$ & $\begin{array}{c}\text { Collapse } \\
\text { prevention }\end{array}$ \\
\hline $\begin{array}{c}\text { Original } \\
\text { structure }\end{array}$ & $31.21 \%$ & $10.93 \%$ & $1.29 \%$ & $0 \%$ \\
$\begin{array}{c}\text { Reinforced } \\
\text { structure }\end{array}$ & $6.94 \%$ & $6.37 \%$ & $0.78 \%$ & $0 \%$ \\
Difference & $24.27 \%$ & $4.56 \%$ & $0.51 \%$ & $0 \%$ \\
\hline
\end{tabular}

\section{CONCLUSIONS}

The SRM of ancient masonry was separately reinforced by organic materials, namely, MER, MMA and SMS, and subjected to tests on performance enhancement. The test results show that the organic material MER greatly improved the compressive strength of cubic SRM specimens, as well as the peak stress, peak strain, ultimate strain and elastic modulus of prism SRM specimens. This means the MER can effectively enhance ancient masonry mortar.

Based on the above tests and the protection criteria of ancient pagodas, this paper puts forward a novel nondestructive approach to reinforce the masonry specimens of brick masonry pagodas, namely, the MER infiltration. The excellence of the proposed approach in reinforcing ancient masonry structures was confirmed through compressive strength test and shear strength test.

The results of the compressive strength test and shear strength test were analyzed in details. On this basis, the stressstrain constitutive relation was established for ancient masonry pagodas, in the light of an abundance of field measurements and the existing constitutive equations for masonry materials under uniaxial compression. 
The MER-reinforced SWG Pagoda, an ancient brick masonry pagoda, was modelled and subjected to seismic vulnerability analysis. The failure probabilities of the reinforced and original structures were compared, revealing that the MER-reinforced structure is less likely to fail under each level than the original structure. Therefore, the MER provides an effective tool and a good reference for nondestructive protection of ancient brick masonry pagodas.

\section{ACKNOWLEDGMENTS}

The research described in this paper was financially supported by the National Natural Science Foundation of China (Grant No.: 51178388), Central University Special Foundation for "Double First-Class" Basic Scientific Research Business of Chang'an University in China (Grant No.: 300104281221).

\section{REFERENCES}

[1] Capozucca, R. (2011). Experimental analysis of historic masonry walls reinforced by CFRP under in-plane cyclic loading. Composite Structures, 94(1): 277-289. https://doi.org/10.1016/j.compstruct.2011.06.007

[2] Capozucca, R., Ricci, V. (2016). Bond of GFRP strips on modern and historic brickwork masonry. Composite Structures, 140:

$540-555$ https://doi.org/10.1016/j.compstruct.2015.12.047

[3] Witzany, J., Cejka, T., Zigler, R. (2011). Problems of masonry strengthening with carbon-and glass fibre fabric. Procedia Engineering, 14: 2086-2093. https://doi.org/10.1016/j.proeng.2011.07.262

[4] Ashraf, M., Khan, A. N., Naseer, A., Ali, Q., Alam, B. (2012). Seismic behavior of unreinforced and confined brick masonry walls before and after ferrocement overlay retrofitting. International Journal of Architectural Heritage, 6(6): 665-688. https://doi.org/10.1080/15583058.2011.599916

[5] Li, Q., Che, J., Ma, C., Liu, H., Wang, D. (2017). Research Summary on the Masonry Structure Reinforcement Technology in China. DEStech Transactions on Engineering and Technology Research, 430-436.

https://doi.org/10.12783/dtetr/iccere2017/18318
[6] Cakir, F., Uckan, E., Shen, J., Seker, S., Akbas, B. (2016). Seismic performance evaluation of slender masonry towers: A case study. The Structural Design of Tall and Special Buildings, 25(4): 193-212. https://doi.org/10.1002/tal.1235

[7] Ashour, A., Galal, K., Farnia, N. (2018). Analytical and experimental study on upgrading the seismic performance of reinforced masonry columns using GFRP and CFRP wraps. Journal of Composites for Construction, 22(4): 04018013. http://dx.doi.org/10.1061/(ASCE)CC.19435614.0000844

[8] Zuo H.L., Li Y.S., Di J., Guo N. (2018). Lateral performance of timber shear walls reinforced by prestressed diagonal cross bars, Annales de Chimie Science des Matériaux, 42(2): 233-243. https://doi.org/10.3166/ACSM.42.233-243

[9] Zhao, Y.G.B., Ding, P.Z., Zhao, Y., Yan, X.W. (2019). Mechanical properties of metallic pseudo rubber-silicon rubber composite for three-way seismic isolation. Revue des Composites et des Matériaux Avancés, 29(6): 341350. https://doi.org/10.18280/rcma.290601

[10] Peng X.L., Fan W., Sun C., Hao G., Zhang Y. (2018). Physical and mechanical properties of interface transition zone between loess and paleosol, Annales de Chimie Science des Matériaux, 42(4): 535-545. https://doi.org/10.3166/ACSM.42.535-545

[11] Huang Z.H., Zhu Z.Q., Li J.Z., Lu G.Y. (2018). Reliability study on the application of reflected wave method in integrity test of pre-stressed pipe pile, Instrumentation Mesure Métrologie, 17(3): 411-422. https://doi.org/10.3166/I2M.17.411-422

[12] GB/T50129-2011 (2011). Standard's Test Method of Basic Mechanics Properties of Masonry. Beijing: China Architecture \& Building Press.

[13] Hendry, A.W., Sinha, B.P., Davies, S.R. (2017). Design of Masonry Structures. CRC Press.

[14] Steinhardt, N.S. (2004). The Tang architectural icon and the politics of Chinese architectural history. The Art Bulletin, $\quad 86(2)$ : 228-254. https://doi.org/10.1080/00043079.2004.10786192

[15] Pang, R., Xu, B., Kong, X., Zou, D. (2018). Seismic fragility for high CFRDs based on deformation and damage index through incremental dynamic analysis. Soil Dynamics and Earthquake Engineering, 104: 432436. https://doi.org/10.1016/j.soildyn.2017.11.017 